\title{
Stereotactic Surgery for Temporal Lobe Epilepsy
}

\author{
Andrew G. Parrent and Andres M. Lozano
}

\begin{abstract}
In light of the recent resurgence of interest in stereotactic functional procedures, the authors have reviewed the role of stereotactic ablative surgery in the treatment of temporal lobe epilepsy. Literature pertaining to stereotactic amygdalotomy, hippocampotomy and fornicotomy is reviewed and summarized. However, the results presented in those early studies are difficult to interpret given the surgical techniques and outcome assessment used. Modern stereotactic ablative surgery using current image-guided technology offers the opportunity to revisit some of these techniques. In recent studies of stereotactic amygdalohippocampotomy, outcomes are not as favorable as those obtained with standard temporal resections. However, these relatively discrete ablative techniques may shed light on the anatomical substrate underlying temporal lobe epilepsy.
\end{abstract}

RÉSUMÉ: La chirurgie stéréotaxique dans l'épilepsie temporale. Dans l'optique d'un regain récent d'intérêt pour les procédures fonctionnelles stéréotaxiques, les auteurs ont revu le rôle de la chirurgie ablative stéréotaxique dans le traitement de l'épilepsie temporale. La littérature concernant l'amygdalotomie stéréotaxique, l'hippocampotomie et la fornicotomie est revue et résumée. Cependant, les résultats présentés dans les études antérieures sont difficiles à interpréter compte tenu des techniques chirurgicales et des moyens d'évaluation des résultats utilisés. La chirurgie ablative stéréotaxique moderne utilisant la technologie sous guidage par imagerie offre l'occasion de revoir certaines de ces techniques. Dans les études récentes de l'amygdalohippocampotomie stéréotaxique, les résultats ne sont pas aussi favorables que ceux obtenus par les résections temporales standards. Cependant, ces techniques ablatives relativement discrètes peuvent éclairer le substrat anatomique sous- jacent à l'épilepsie temporale.

Can. J. Neurol. Sci. 2000; 27: Suppl. 1 - S79-S84

There has been a resurgence of interest in stereotactic procedures for epilepsy and functional neurosurgical disorders. There are several factors responsible for this. The most important is the significant improvement in brain imaging which has come as a consequence of the development of computerized tomography and, in particular, magnetic resonance imaging (MRI). These procedures have improved the spatial definition and resolution of imaging and have made image-guided surgery easier, more accurate and more accessible to mainstream neurosurgery. The improvements in imaging have worked in concert with an increased understanding of the pathophysiology of epilepsy disorders such that the identification and selection of targets has a stronger scientific rationale than was previously available. In addition to these important developments, there is a large historical basis for the use of stereotactic procedures in the treatment of epilepsy with some interesting if not promising initial results.

Finally the general trend towards minimally invasive surgery is responsible for the need to re-examine stereotactic procedures. With the trend towards minimizing surgical exposure and patient discomfort and shortening hospital stay, there will be a further need to re-examine the use of stereotactic functional procedures.
Stereotactic procedures have the possibility of being highly accurate, more economical and better tolerated than conventional craniotomy and resective surgery.

Several strategies can be pursued with stereotactic and functional neurosurgery. The first strategy is to destroy the seizure focus in a minimally invasive manner. Such a targeted approach requires strong physiologic evidence of the seizure focus together with precise as possible anatomical delineation with modern imaging. A second strategy may be to decrease the epileptogenic volume, in this way reducing seizure burden and, at least in theory, putting intrinsic brain mechanisms as well as anticonvulsants in a better position to deal with the epileptic tendency. A third use of stereotaxy is for the interruption of the

From the Division of Neurosurgery, Department of Clinical Neurological Sciences, London Health Sciences Centre, London ON, Canada (AGP) and the Division of Neurosurgery, The Toronto Hospital, Toronto ON, Canada (AML).

Reprint requests to: A.Parrent, Division of Neurosurgery, Department of Clinical Neurological Sciences, London Health Sciences Centre, 339 Windermere Road,

London ON, N6A5A5 Canada 
pathways of seizure propagation. Because of the high precision of these techniques, discrete axonal projections can be interrupted, thereby disconnecting the seizure source from adjacent or remote brain structures. Further strategies that are possible with stereotactic neurosurgery are the destruction or modulation of brain structures which may have an influence on seizure tendency; thalamic lesioning may reduce cortical excitability and thus epileptogenesis. ${ }^{1}$

Several surgical techniques are available to the stereotactic neurosurgeon. They have in common the possibility of delivering a physical destructive force to ablate neural tissues and include mechanical and energy sources. In the past, everything from mechanical undercutting with leucotomy to heat, cold, wax, and alcohol have been used. More recently, radiofrequency lesioning has become popular. There is also a trend toward using external ionizing radiation such as is available with the gamma knife, linear accelerator and proton beam to place highly selective discrete lesions in the brain. Other modalities that have been used include the insertion of radioactive seeds such as yttrium 90 as a source of brachytherapy to create localized lesions within the brain.

It is tempting to speculate on the future use of other modalities such as excitatory amino acids to selectively lesion neuronal cells bodies at the epileptic focus or perhaps the use of chronic electrical deep brain stimulation to modulate seizure tendency as has been used quite effectively in Parkinson's disease and pain disorders. Similar deep brain stimulation of the thalamus has already shown some promise in the treatment of epilepsy and this modality of therapy requires further investigation.

\section{INTRODUCTION}

Human stereotactic surgery was introduced in the 1940s and initially used for the treatment of psychiatric disorders and chronic pain. Its use then spread to include the treatment of movement disorders and epilepsy. In spite of the numerous technical refinements that have occurred since its introduction, the basic principles of stereotactic surgery remain the same.

Conventional stereotactic surgery requires that the patient be fitted with a rigid frame directly attached to the skull. This device is designed to provide a fiducial marker system as well as a platform for mounting instruments during surgery. Structures within the brain can then be localized and registered with the fiducials through a number of imaging techniques. Initially, ventriculography was used to identify standard internal landmarks such as the anterior and posterior commissures or the foramen of Monroe. The location of surrounding deep brain structures could then be extrapolated from these landmarks using atlases of cerebral anatomy. ${ }^{2,3,4}$ When possible, target location was confirmed intraoperatively using physiological techniques such as electrical stimulation and/or recording.

The introduction of CT and MRI allowed direct visualization of cerebral anatomy and direct targeting of normal brain structures or pathological lesions. Since then, stereotactic biopsy has become the most common application of stereotactic technique. Functional neurosurgery continues to rely on the identification of recognizable internal cerebral landmarks such as the anterior and posterior commissures. CT and MRI rather than ventriculography are now used to identify these landmarks and standard atlases are used to determine the preliminary target site supplemented by physiologic identification of the target or surrounding structures with micro- or semimicroelectrode recording and/or electrical stimulation.

\section{STEREOTACTIC SURGERY FOR EPILEPSY}

Stereotactic surgery has been used for the treatment of epilepsy since the 1950s. However, it has never been a widely accepted form of treatment and there is no agreement on criteria for patient selection, nor on the specific target sites for a particular disorder. While there are numerous articles in the literature describing the various stereotactic procedures, analysis of these papers is complicated by a number of factors:

1. Most studies were done prior to the establishment of a uniform classification of seizures, making it difficult to determine the nature of the seizure disorder treated by a particular lesion.

2. Often, multiple subcortical targets were used in individual patients, making it difficult to assess the role of a specific target for a specific condition.

3. There is sufficient variability in the location of particular subcortical nuclei with respect to internal reference points, that in many cases it is uncertain whether unsuccessful surgery was a result of inaccurate localization, incomplete destruction, or inappropriate selection of the target.

4. There has been a tendency to reserve stereotactic surgery for particularly complex and intractable seizure problems. This philosophy may have eliminated some of the more straightforward disorders for which the procedures may have been effective.

\section{HistoricAl BACKGROUND}

Recognition of the role of medial temporal structures in the production of complex partial seizures made these structures attractive areas for stereotactic ablation. The effectiveness of lesions in this region also became apparent as a spin-off of stereotactic amygdalar ablation for aggressive behaviour disorders in which many of the patients were also epileptic. ${ }^{5}$ The rationale for ablation of medial temporal lobe structures (ie. amygdala, hippocampus) was based on the premise that even if these nuclei were not the actual epileptic focus, the spread of an epileptogenic discharge from the temporal lobe was largely through the amygdala and hippocampus to the hypothalamus and thalamus. Hence, lesions have been placed in the amygdala and hippocampus as well as the outflow and downstream structures (fornix, hypothalamus, thalamus) in the treatment of temporal lobe epilepsy. These are summarized in the Table and discussed below.

\section{STEREOTACTIC AMYGDALOTOMY, HIPPOCAMPOTOMY}

In 1963, Narabayashi performed stereotactic unilateral or bilateral amygdalotomies in a group of patients with behaviour disorders characterized by hyperexcitability, assaultive behaviour and aggression, with or without epilepsy. ${ }^{5}$ While the aim of the surgery was control of the behaviour disorder, it was also found that seizures were improved in some patients. Of 25 patients, mainly children with predominantly grand mal seizures, 
nine became seizure-free (six free of medication) and seizures decreased in eight. ${ }^{6}$ The degree of behavioural improvement paralleled the decrease in seizures. In general, the benefit for temporal lobe, psychic and visceral seizures was not sustained. In four such cases, seizures ceased immediately following surgery with recurrence to preoperative seizure frequency within a year. Narabayashi ${ }^{7}$ felt that the small amygdalar lesions were probably insufficient to control this type of epilepsy.

Schwab et $\mathrm{al}^{8}$ made amygdalar lesions in 10 patients with temporal lobe epilepsy. In all patients, a unilateral anterior mesial temporal focus was found by depth electrode monitoring, and a small $(6 \times 7 \mathrm{~mm})$ lesion was placed in the posterior amygdala, aiming to cut this focus off from the cortical surface. Three patients became seizure-free and four experienced significant reduction in seizure severity and frequency. Heimburger et $\mathrm{al}^{9}$ performed amygdalotomy in 58 patients for control of seizures and/or behaviour disorders. Seizures were described as psychomotor, petit mal and grand mal. Amygdalotomy was performed ipsilateral to the epileptic discharge, when present. When preoperative data were nonlocalizing, unilateral nondominant amygdalotomy was performed; later in the Heimburger series, bilateral procedures were carried out in this group. Over a 1-11 year follow-up period, seizures were 'improved' in 50\%, with psychomotor seizures responding the best. ${ }^{10}$ Vaernet ${ }^{11}$ reported the results of amygdalotomy in 45 patients with temporal lobe epilepsy followed for more than one year. Of 27 patients undergoing unilateral amygdalotomy for a unilateral focus, five became seizure-free and 10 experienced greater than $50 \%$ reduction of seizure frequency; with bilateral amygdalotomies in four patients with bilateral foci, two were seizure-free and two significantly improved.
In a number of studies, lesions were placed in the hippocampus as well as the amygdala. In a group of 16 patients with temporal lobe seizures studied by chronic depth recording, Flanigin and Nashold ${ }^{12}$ produced lesions in areas characterized by maximal interictal spiking and spontaneous or stimulationinduced seizure onset. Procedures included unilateral amygdalar or hippocampal lesions, unilateral combined amygdalar and hippocampal lesions and bilateral amygdalar lesions. Some patients received additional thalamic lesions. Four patients were rendered seizure-free or markedly improved, six were improved and six unchanged.

The series of Mempel et $\mathrm{al}^{13}$ consisted of 70 patients with behaviour disorders and various types of seizures. Acute bilateral depth recordings were carried out and various combinations of unilateral or bilateral amygdalar and/or hippocampal lesions were made. Ten patients underwent stereotactic ablations contralateral to previous temporal lobectomy. Overall, $11.4 \%$ became seizure-free with significant improvement in a further $74.3 \%$. Nadvornik et al ${ }^{14,15}$ devised a technique to longitudinally lesion the hippocampus enabling more extensive ablation. In eight patients with well defined unilateral temporal foci, five were rendered seizure-free, one had auras only and two had infrequent seizures.

Talairach and Szikla ${ }^{16}$ created lesions in 14 patients with partial seizures and temporal foci by stereotactically implanting yttrium 90 pellets in the amygdala and hippocampus. Over a period of 7-14 months seizures stopped in nine and decreased in frequency in two others.

Early experience with ablation of the amygdala and hippocampus showed that lesioning could be carried out safely. The risks and complications of medial temporal stereotactic

Table: Selected results of stereotactic ablations for temporal lobe epilepsy

\begin{tabular}{|c|c|c|c|}
\hline Authors & Procedures & \# Cases & Outcome \\
\hline Narabayashi \& Mitzumi (1970) & amygdalotomy & 25 & 9 - seizure-free; 8 - decreased seizures \\
\hline Schwab et al (1965) & amygdalotomy & 10 & 3 - seizure-free; 4 - decreased seizures \\
\hline Heimburger et al (1978) & unilateral or bilateral amygdalotomy & 58 & $50 \%$ - improved \\
\hline Vaernet (1972) & $\begin{array}{l}\text { unilateral amygdalotomy } \\
\text { bilateral amygdalotomy }\end{array}$ & $\begin{array}{l}27 \\
4\end{array}$ & $\begin{array}{l}5 \text { - seizure-free; } 10 \text { - >50\% reduction } \\
2 \text { - seizure-free; } 2 \text { - improved }\end{array}$ \\
\hline Flanigin \& Nashold (1976) & $\begin{array}{l}\text { unilateral or bilateral amygdalotomy; hippocampotomy; } \\
\text { amygdalohippocampotomy +/- thalamotomy }\end{array}$ & 16 & $\begin{array}{l}4 \text { - seizure-free; } 6 \text { - improved; } \\
6 \text { - unchanged }\end{array}$ \\
\hline Mempel et al (1980) & unilateral or bilateral amygdalotomy +/- hippocampotomy & 70 & $\begin{array}{l}11.4 \% \text { - seizure-free; } \\
74.3 \% \text { - improved }\end{array}$ \\
\hline Nadvornik et al (1975) & hippocampotomy & 8 & $\begin{array}{l}5 \text { - seizure-free; } 1 \text { - auras; } \\
2 \text { - infrequent seizures }\end{array}$ \\
\hline Talairach \& Szikla (1965) & yttrium 90, amygdalar and hippocampal lesions & 14 & 9 - seizure-free; 2 - reduced seizures \\
\hline Umbach (1966) & $\begin{array}{l}\text { unilateral or bilateral fornicotomy }+/- \text { lesions } \\
\text { in amygdala, hippocampus, lamella medialis, pallidum }\end{array}$ & 18 & $\begin{array}{l}5 \text { - seizure-free; } 11 / 13 \text { free of } \\
\text { grand mal seizures }\end{array}$ \\
\hline Bouchard \& Umbach (1972) & $\begin{array}{l}\text { unilateral or bilateral fornicotomy }+/- \text { lesions in } \\
\text { amygdala, hippocampus, lamella medialis, pallidum }\end{array}$ & 50 & $\begin{array}{l}65 \% \text { decrease in grand mal seizures; } \\
62 \% \text { decrease in minor seizures }\end{array}$ \\
\hline Schaltenbrand et al (1966) & fornicotomy $+/$ - anterior commissurotomy & 5 & 3 - improved \\
\hline
\end{tabular}


lesions in most reports are few. Bilateral amygdalar lesions were not attended by long term memory difficulty or the Kluver-Bucy syndrome, although bilateral hippocampal lesions were felt to carry higher risks and were consequently avoided. ${ }^{17}$ Although a proportion of patients demonstrated significant seizure reduction, the results were not as dramatic as temporal lobectomy. This may be due to a number of factors:

1. In many of the studies, ablative surgery was carried out for behaviour disorders rather than epilepsy. The reported seizure control reflects all forms of epilepsy present in the study population, potentially obscuring a beneficial effect for a specific seizure subtype.

2. The concept of lesioning amygdala and sparing hippocampus may be unsound in the epileptic temporal lobe with seizures arising from the intact hippocampus.

3. The technology of the time permitted only ventriculographic localization of amygdalar and hippocampal targets with its inherent inaccuracy. It was not possible to image the lesioned area postoperatively to determine the anatomical extent, and therefore the adequacy of the lesion. Insufficient hippocampal and/or amygdalar lesioning may have allowed persistent epileptogenesis.

\section{FORNIX LESIONS}

Umbach $^{18,19}$ performed unilateral fornicotomy in 20 patients and bilateral fornicotomy in five patients with temporal lobe epilepsy, placing lesions in the fornix at the posterior margin of the anterior commissure. Additional lesions were made in the amygdala, hippocampus, lamella medialis and pallidum in some patients. Of 18 cases followed for 3-11 years, five became seizure-free and 11 of 13 patients were relieved of their grand mal seizures. In a later review of more than 50 cases, Bouchard and $\mathrm{Umbach}^{20}$ reported a decrease in grand mal seizures by $65 \%$, minor seizures by $62 \%$ and improvement in associated psychic disturbances in $50 \%$. Schaltenbrand et $\mathrm{a}^{21}$ noted improvement in three of five patients with psychomotor seizures after fornicotomy, usually combined with anterior commissure lesions.

Bilateral fornix lesions did not appear to produce adverse behaviour or personality changes, nor any disturbance in memory.

\section{CURRENTAPPLICATIONS OF STEREOTACTIC ABLATION FOR EPILEPSY}

There are few reports in the recent literature regarding stereotactic surgery for the treatment of epilepsy. Patil and Torkilson $^{22}$ described multiple interventions for epilepsy in 24 patients with seizures of multilobar origin. Their technique involved a combination of topectomy, multiple subpial transection and/or amygdalohippocampal radiofrequency ablation (amygdalohippocampotomy). Three of their patients with seizures of mesial temporal origin underwent stereotactic amygdalohippocampotomy with excellent results (seizure-free or rare seizures). This procedure involved CT-guided identification of the amygdala and hippocampus for stereotactic targeting. A radiofrequency lesion measuring $11 \times 15 \mathrm{~mm}$ was then made in each of these structures. ${ }^{23}$

Parrent and Blume ${ }^{24}$ performed stereotactic amygdalotomy in
19 patients with temporal lobe epilepsy. All patients were shown to have mesial temporal originating seizures by continuous EEG monitoring +/- subdural electrography, and all recorded seizures originated from the temporal lobe that was ultimately subject to ablation. Surgical planning involved identification of the amygdala and hippocampus on stereotactically acquired MRI scans, and postoperative MRI confirmed the accuracy of targeting. In five patients who underwent limited lesioning (mean, 6.4 lesions; range 4-11) a favorable seizure outcome (defined as seizure-free, auras only, or $>90 \%$ seizure reduction) was obtained in only one patient (20\%). However, 15 patients (one of whom had previously undergone limited lesioning) underwent extensive lesioning designed to produce a large confluent area of ablation (mean, 26.0 lesions: range, 12-54). In this group, nine $(60 \%)$ achieved a favorable outcome and post operative MRI demonstrated extensive ablation of the amygdala and hippocampus, sparing the parahippocampal gyrus.

The gamma knife was used by Regis et $\mathrm{al}^{25}$ to produce radiosurgical lesions in the amygdala, hippocampus and entorhinal cortex of patients with temporal lobe epilepsy. MRI imaging was used for target delineation and dose planning, and a dose of 25 Gy was administered at the $50 \%$ isodose line. Seizure reduction occurred in a delayed fashion over a 3-18 month period coincident with development of MRI signal changes and then atrophy in the radiated structures. A subsequent multicenter European study by the same group using the same technique in 21 patients found that seizure frequency decreased progressively in the first nine months following radiosurgery and all patients followed $>10$ months were seizure-free. ${ }^{26} \mathrm{MRI}$ changes appeared in the amygdaloentorhinohippocampal region around the ninth month, with gradual normalization in most patients over the next three to four months. Heikkinen et $\mathrm{al}^{27}$ treated a single patient with temporal seizures by stereotactically radiating the pes hippocampus. A lower radiation dose of $10 \mathrm{~Gy}$ was used and the MRI scan at 30 months showed no changes in the radiated structures. Seizures ceased seven months following treatment and had not recurred at 27 months. Radiosurgery, at doses that produce atrophy, presumably works through destruction of the epileptogenic target. However, the mechanism for efficacy of lower dose radiosurgery is not known. This must involve changes in the neuronal network involved in seizure generation. Larger series and longer follow-up will be needed with both techniques to assess long-term benefit as well as the potential delayed side-effects of radiation.

\section{DiscuSSION}

Temporal lobectomy is considered to be an effective treatment for unilaterally originating mesial temporal seizures. In a survey conducted prior to the 1992 Palm Desert Conference on the Surgical Treatment of the Epilepsies, Engel reported that $68 \%$ of patients followed for at least one year were seizure-free and $24 \%$ improved following anterior temporal lobectomy. ${ }^{28}$ In a five year follow-up of 92 patients after temporal lobectomy, Haglund and Ojemann ${ }^{29}$ found that $51-57 \%$ were seizure-free in any given year, with $32 \%$ remaining seizure-free for five years.

In recent years, selective amygdalohippocampectomy has gained acceptance in the treatment of temporal lobe epilepsy. In this procedure the amygdala, hippocampus and a variable portion of the parahippocampal gyrus are resected through a corridor in 
the temporal lobe or anterior temporal stem leaving the temporal neocortex intact. Wieser ${ }^{30}$ reported on 177 patients undergoing selective amygdalohippocampectomy with $59 \%$ seizure-free, $7 \%$ having rare seizures and $11 \%$ experiencing $>90 \%$ seizure reduction. In 30 patients without tumours, vascular malformations or hamartomas, $73 \%$ became seizure-free and $20 \%$ had rare seizures. Such results compare favourably with temporal lobectomy.

There is evidence to suggest that selective removal of mesial temporal structures may be as effective as lobectomy when seizure origin is confined to these structures. Stereotactic placement of lesions in the mesial temporal lobe could theoretically provide a less invasive means of achieving this end, while avoiding the potential morbidity of open resection.

In patients receiving extensive amygdalohippocampal ablation, $60 \%$ obtained favorable outcomes but only $13 \%$ were seizure-free. ${ }^{24}$ These outcomes are not as good as one would expect following temporal lobectomy or selective amygdalohippocampectomy in a similar group of patients and indicate the persistence of epileptogenic tissue. It is possible that remnants of the amygdala and/or hippocampus within the lesioned area may be sufficient to generate continuing seizures. If this is the case, then better lesion planning and more extensive ablation may result in an improved outcome. Further follow-up studies will be needed to determine whether this strategy translates into better seizure control.

Although it is possible that lesioning, in some way, produces a new epileptogenic focus, the fact that patients' continuing seizures were similar to their preoperative seizures suggests that these result from persistence of an old focus rather than production of a new one. It may be that selective ablation of the amygdala and hippocampus alone is insufficient to control seizures in some patients. Wieser ${ }^{30}$ indicated that incomplete removal of the parahippocampal gyrus, in particular the subiculum, during selective amygdalohippocampectomy resulted in less satisfactory seizure control. Goldring et $\mathrm{al}^{31}$ have also postulated a pivotal role for the parahippocampal gyrus specifically the entorhinal cortex - in seizure control following temporal lobe resection. Extension of lesions into this area may be necessary to control seizures in some patients, although it is unclear at present how one might distinguish those patients for whom restricted lesioning within the amygdala and hippocampus is sufficient, from those who require additional parahippocampal lesions.

\section{SUMMARY}

1. Stereotactic lesioning in the medial temporal lobe has produced favourable results in a number of patients. However, the decrease in seizure frequency is not as dramatic as that following temporal lobectomy in properly selected cases. This technique is undergoing continual modification and further study will be needed to assess its ultimate role in the treatment of temporal lobe epilepsy. Indeed, a case could be made for considering stereotactic treatment as an initial treatment given the low morbidity, rapid postoperative recovery time and high level of patient acceptance, with temporal lobectomy reserved for those patients achieving inadequate seizure control.

2. Lesioning techniques may be applicable in patients with bilaterally originating temporal seizures. Bilateral lesions confined to the amygdala have been shown to be safe from a neuropsychologic standpoint, and may be useful in this group of patients. ${ }^{10,11,17,19}$

3. Similarly, patients who have undergone temporal lobectomy and continue to experience seizures from the contralateral temporal lobe might be considered for lesioning of the remaining amygdala.

4. Given the changes in stereotactic technique over the last few decades, the role of other procedures (eg. fornicotomy) should be reassessed as possible adjunctive therapy for difficult cases of temporal lobe epilepsy.

5. The use of radiosurgery for lesion production is less invasive than radiofrequency ablation, and may prove to be safer. Its role in epilepsy treatment needs further investigation.

\section{REFERENCES}

1. Morillo LE, Ebner TJ, Bloedel JR. The early involvement of subcortical structures during the development of a cortical seizure focus. Epilepsia 1972; 13: 597-608.

2. Andrew J, Watkins ES. A stereotactic atlas of the human thalamus and related structures. A variability study. Baltimore, Williams \& Wilkins, 1969.

3. Schaltenbrand G, Bailey P. Introduction to Stereotaxis with an Atlas of the Human Brain. Stuttgart: Thieme, 1959.

4. van Buren MJ, MacCubbin DA. An outline atlas of the human basal ganglia with estimation of anatomical variation. J Neurosurg 1962; 19: 811-839.

5. Narabayashi H, Nagao T, Saito Y, Yoshida M, Nagahata M. Stereotaxic amygdalotomy for behavior disorders. Arch Neurol 1963; 9: 1-16.

6. Narabayashi H, Mizutani T. Epileptic seizures and the stereotaxic amygdalotomy. Confin Neurol 1970; 32: 289-297.

7. Narabayashi H. From experiences of medial amygdalotomy on epileptics. Acta Neurochir 1980; suppl. 30: 75-81.

8. Schwab RS, Sweet WH, Mark VH, Kjellberg RN, Ervin FR. Treatment of intractable temporal lobe epilepsy by stereotactic amygdala lesions. Trans Am Neurol Assoc 1965; 90: 12-19.

9. Heimburger RF, Small IF, Milstein V, Moore D. Stereotactic amygdalotomy for convulsive and behavioral disorders. Appl Neurophysiol 1978; 41: 43-51.

10. Heimburger RF, Whitlock CC, Kalsbeck JE. Stereotaxic amygdalotomy for epilepsy with aggressive behavior. JAMA 1966; 198: 741-745.

11. Vaernet K. Stereotaxic amygdalotomy in temporal lobe epilepsy. Confin Neurol 1972; 34: 176-180.

12. Flanigin HF, Nashold BS. Stereotactic lesions of the amygdala and hippocampus in epilepsy. Acta Neurochir 1976; suppl. 23: 235-239.

13. Mempel E, Witkiewicz B, Stadnicki R, et al. The effect of medial amygdalotomy and anterior hippocampotomy on behavior and seizures in epileptic patients. Acta Neurochir 1980; suppl. 30: 161-167.

14. Nadvornik P, Sramka M. Anatomical considerations for the stereotaxic longitudinal hippocampectomy. Confin Neurol 1975; 36: $177-181$.

15. Nadvornik P, Sramka M, Gajdosova D, Kokavec M. Longitudinal hippocampectomy. Confin Neurol 1975; 37: 244-248.

16. Talairach J, Szikla G. Destruction partielle amygdalohippocampique par l'yttrium 90 dans le traitement de certaines epilepsies rhinencephalique. Neuro-Chirurgie 1965; 11: 233-240.

17. Narabayashi H. Discussion of K. Vaernet, Stereotactic amygdalotomy in temporal lobe epilepsy. Confin Neurol 1972; 34: 182 .

18. Umbach W. Elektrophysiologisch und vegetative Phanomene bei stereotaktischen Hirnoperationen. Berlin/Heidelberg/New York: Springer, 1966.

19. Umbach W. Long-term results of fornicotomy for temporal epilepsy. Confin Neurol 1966; 27: 121-123. 
20. Bouchard G, Umbach W. Indications for open and stereotactic brain surgery in epilepsy. In: I Fusek, Z Kunc, eds. Present limits of neurosurgery. Amsterdam: Excerpta Medica, 1972: 403-406.

21. Schaltenbrand G, Spuler H, Nadjimi M, Hopf H, Wahren W. Die stereotaktische Behandlung der Epilepsien. Confin Neurol 1966; 27: 111-113.

22. Patil AA, Torkelson AR. Minimally invasive surgical approach for intractable seizures. Stereotact Funct Neurosurg 1995; 65: 86-89.

23. Patil AA, Andrews R, Torkelson R. Stereotactic volumetric radiofrequency lesioning of intractable seizures. Stereotact Funct Neurosurg 1995; 64: 123-133.

24. Parrent AG, Blume WT. Stereotactic amygdalohippocampotomy for the treatment of medial temporal lobe epilepsy. Epilepsia 1999; 40: 1408-1416.

25. Regis J, Rey M, Genton P, et al. Gamma knife surgery instead of epilepsy surgery for mesial temporal lobe epilepsy. Epilepsia 1966; 37, suppl. 5: 182.
26. Regis J, Rey M, Vladyka V, et al. Gamma knife for mesial temporal lobe epilepsy: preliminary results of the European multicentric controlled study. Epilepsia 1998; 39 suppl 6: 91.

27. Heikkinen ER, Heikkinen MI, Sotaniemi K. Stereotactic radiotherapy instead of conventional epilepsy surgery. A case report. Acta Neurochir (Wein) 1992; 119: 159-160.

28. Engel J Jr, Van Ness P, Rasmussen T, et al. Outcome with respect to seizures. In: Engel J Jr, ed. Surgical Treatment of the Epilepsies ed 2. New York, Raven Press, 1992: 609-622.

29. Haglund MM, Ojemann LM. Seizure outcome in patients undergoing temporal lobe resections for epilepsy. In: Neurosurgery Clinics of North America 1993; 4(2): 337-344.

30. Wieser HG. Selective amygdalohippocampectomy: indications and follow-up. Can J Neurol Sci 1991; 18: 617-627.

31. Goldring S, Edwards I, Harding GW, Bernardo KL. Results of anterior temporal lobectomy that spares the amygdala in patients with complex partial seizures. J Neurosurg 1992; 77: 185-193. 